\title{
Measurement Method of Sustainability of Higher Education System
}

\author{
Jiayu $\mathrm{Lu}^{1 *}$ \\ ${ }^{1}$ School of Business Administration, Northeastern University, Shenyang,Liaoning, China, 110000. \\ *Corresponding author. Email:lu756171128@163.com
}

\begin{abstract}
The higher education system (HES) consists of universities and research institutions. It is a training base for high-quality talents and a vital source of scientific and technological innovation, so the sustainability of higher education system (SS) should be highly valued. The research selects the HES of 50 countries, which is relatively complete. To measure the SS, the research compares the higher education system with the natural ecosystem, and find that the key is the efficient circulation. In innovation activities, universities, research institutions and enterprises have formed a circulation in the flow of innovation elements such as funds, talents and innovation achievements. Therefore, the research propose the collaborative innovation efficiency of University- Research-Industry (URI) as an indicator to measure SS. To quantify SS, established a network data envelopment analysis (DEA) model. The research used five input indicators, one intermediate indicator and three output indicators, which have a certain degree of innovation. The results show that although no country's HES is completely sustainable, SS in developed countries such as the United States is at the forefront. Finally, the research gives some policy suggestions to improve the sustainability of HES.
\end{abstract}

Keywords: Higher education system (HRS), Sustainability score (SS),University-Research-Industry (URI), Network data envelopment analysis (DEA).

\section{INTRODUCTION}

In this era of rich knowledge and full of innovation, higher education is undoubtedly the incubation base for people to broaden their horizons, develop their abilities and apply innovation. As time goes by, higher education has accumulated experience, expanded its scale and gradually formed a higher education system. Although it has greater influence than in the past, there are still worries about the future: Can the higher education system operate for a long time? People are calling for the introduction of a sustainable evaluation system for the higher education system.

"Sustainable system" is the concept of ecology, which is defined as the system that can maintain its effectiveness over time. The ecosystem receives the input of solar energy, maintains its effective operation through the material cycle and energy cycle, and outputs organic matter, inorganic salt and oxygen. Different from the natural the ecosystem, HES is a social system, but the research can analyze them by analogy. Just like ecosystem, HES also needs the input of funds, teachers, researchers and students to produce academic and scientific research results, and continuously output innovative talents to society and enterprises. However, what makes a system sustainable is the existence of circulation. For HES, innovation is the fundamental driving force of its sustainable development, without which the outputs of HES mentioned above can never exist. Therefore, to quantify the sustainability of HES, its innovation circulation needs to be defined.

\section{NETWORK DATA ENVELOPMENT ANALYSIS MODEL: EVALUATING THE SUSTAINABILITY OF THE HIGHER EDUCATION SYSTEM}

\subsection{Defining a sustainable HES: From Triple Helix Theory to Collaborative Innovation Efficiency}

Due to the scarcity of government financial expenditure, the funds provided by the government for HES are often limited. If there is a lack of funds, it is difficult for HES to provide reliable support for teaching 
and scientific research activities and attract high-quality teachers and students. Faced with this innovation dilemma, one way is to introduce the help of enterprises. Enterprises cooperate with universities and scientific institutes via teaching and research projects to provide funds for them. Enterprises also provide innovative inspiration for HES researchers through experiences and problems in production practice. Funded colleges and universities can in turn provide enterprises with a steady stream of high-tech talents and advanced technologies through teaching and scientific research, and at the same time strengthen their teachers and students. This realizes the collaborative participation of University-Research-Industry(URI) in innovation activities and constitutes a sustainable circulation of HES in a country.

The triple helix theory provides a powerful tool to explain the circulation of HES. According to the different orientations of enterprises, colleges and universities, and scientific institutions, the research can construct a triple helix structure of University-Research-Industry with "innovation" as the core [1]. The triple helix structure can continue to be deconstructed into a circular structure of University-Research-Industry collaborative innovation. This circulation structure vividly defines the sustainability of HES. Enterprises provide educational funds for universities to train students, university students enter scientific research institutions to provide scientific research talents, and scientific research institutions provide scientific research and innovation achievements for enterprises. On the contrary, scientific research institutions provide professors for universities to train students, universities provide employees for enterprises, and enterprises provide scientific research funds for scientific research institutions. URI can provide each other with what they need and realize a virtuous circle of resources.

At the same time, a sustainable system requires input and output to be economically efficient. If the government and enterprises invest a lot of funds and equipment into universities and scientific institutions, but their output is limited, it will lead to the unsustainable model of URI collaborative innovation. Therefore, the research use the index of University-Research-Industry collaborative innovation efficiency to characterize the Sustainability Score (SS) of HES in a country.

\subsection{Network Data Envelopment Analysis Model}

Data envelopment analysis (DEA), as a non-parametric approach, doesn't require artificially assigning weight values to each input-output index, based on mathematical programming, the production frontier is estimated according to the inputs and outputs of each decision-making unit (DMU) [2]. HES in a country can be regarded as a DMU. The production frontier is an economic concept composed of Pareto optimal solutions with the minimum input and the maximum output as the objectives [3]. The relative effectiveness of each DMU is calculated according to the distance between each DMU and the production boundary. Considering that the chain structure has two stages: "learning to research" and "research to production" respectively, the research use a Two-stage DEA model to measure the sustainability of the HES-Network DEA model. The model can measure the efficiency of these two stages respectively as well as the whole stage.

The HES of country $i$ is $\operatorname{DMU}_{i}(i=1,2, \ldots, n)$. There are $s(s=1,2)$ stages in the whole process, the input variables are $\mathrm{I}_{\mathrm{i}}^{\mathrm{S}}$ and output variables are $\mathrm{O}_{\mathrm{i}}^{\mathrm{S}}\left(\mathrm{I}_{\mathrm{i}}^{\mathrm{S}} \in\right.$ $\left.\mathrm{R}_{+}^{\alpha s}, \mathrm{O}_{\mathrm{i}}^{\mathrm{s}} \in \mathrm{R}_{+}^{\beta s}\right)$. The intermediate variables of stage $\mathrm{s}$ and stage $\mathrm{s}+1$ are set to $\mathrm{P}_{\mathrm{i}}^{(\mathrm{s}, \mathrm{s}+1)}$ and satisfy $\mathrm{P}_{\mathrm{i}}^{(\mathrm{s}, \mathrm{s}+1)} \in \mathrm{R}_{+}^{\gamma(\mathrm{s}, \mathrm{s}+1)} . \alpha, \beta$, and $\gamma$ denote the number of input variables, output variables, and intermediate variables. $\alpha=1,2, \ldots, \mathrm{x} ; \beta=1,2, \ldots, \mathrm{y}$ and $\gamma=$ $1,2, \ldots, z$. $\lambda_{i}^{s}$ is the weight of the model, $\omega^{s}$ is the weight variable of stage $\mathrm{s}$, and $\mathrm{DMU}_{\mathrm{i}}(\mathrm{i}=$ $1,2, \ldots, n)\left(\lambda_{i}^{s} \in R_{+}^{n}\right) . \mu_{x}^{s-}$ is relaxation variable of the input and $\mu_{\mathrm{x}}^{\mathrm{s}+}$ is relaxation variable of the output. The objective function $\theta$ decreases strictly with $\mathrm{I}_{\mathrm{x}_{0}}^{\mathrm{S}}$ and $\mathrm{O}_{\mathrm{y}_{0}}^{\mathrm{S}}$, which satisfies $0<\theta \leq 1 . \theta<1$ indicates a reduced efficiency in $\mathrm{DMU}_{\mathrm{i}}$. When $\theta=1, \mathrm{DMU}_{\mathrm{i}}$ is completely efficient [1]. The target of the network DEA model, $\theta^{*}$, can be expressed as:

$$
\begin{aligned}
& \theta^{*}=\min \theta\left(\mathrm{I}_{\mathrm{x}_{0}}^{\mathrm{S}}, \mathrm{O}_{\mathrm{y}_{0}}^{\mathrm{S}}\right)=\min \frac{\sum_{\mathrm{s}=1}^{2} \omega^{\mathrm{s}}\left[1-\frac{1}{\alpha}\left(\sum_{\mathrm{x}=1}^{\alpha} \frac{\mu_{\mathrm{x}}^{\mathrm{S}-}}{\mathrm{I}_{\mathrm{x}_{0}}}\right)\right]}{\sum_{\mathrm{s}=1}^{2} \omega^{\mathrm{s}}\left[1-\frac{1}{\beta}\left(\sum_{\mathrm{y}=1}^{\beta} \frac{\mu_{\mathrm{X}}^{\mathrm{S}}}{\mathrm{I}_{\mathrm{y}_{0}}^{\mathrm{S}}}\right)\right]} \\
& \text { s.t. }\left\{\begin{array}{c}
\mathrm{I}_{0}^{\mathrm{S}}=\sum_{\mathrm{i}=1}^{\mathrm{N}} \lambda_{\mathrm{i}}^{\mathrm{S}} \mathrm{I}_{\mathrm{i}}^{\mathrm{S}}+\mu^{\mathrm{s}-} \\
\mathrm{O}_{0}^{\mathrm{s}}=\sum_{\mathrm{i}=1}^{\mathrm{N}} \lambda_{\mathrm{i}}^{\mathrm{s}} \mathrm{O}_{\mathrm{i}}^{\mathrm{s}}+\mu^{\mathrm{s}+} \\
\mathrm{P}^{(\mathrm{s}, \mathrm{s}+1)} \lambda^{\mathrm{s}+1}=\mathrm{P}^{(\mathrm{s}, \mathrm{s}+1)} \lambda^{\mathrm{s}} \\
\sum_{\mathrm{i}=1}^{\mathrm{N}} \lambda_{\mathrm{i}}^{\mathrm{s}}=\sum_{\mathrm{s}=1}^{2} \omega^{\mathrm{s}}=1 \\
\lambda_{\mathrm{i}}^{\mathrm{s}}, \mu^{\mathrm{s}}, \mu^{\mathrm{s}}, \omega^{\mathrm{s}} \geq 0
\end{array}\right.
\end{aligned}
$$

The efficiency of stage s can be expressed as:

$$
\theta_{\mathrm{s}}=\frac{1-\frac{1}{\alpha}\left(\sum_{\mathrm{x}=1}^{\alpha} \frac{\mu_{\mathrm{x}}^{\mathrm{s}-*}}{\mathrm{I}_{\mathrm{x}_{0}}^{\mathrm{S}}}\right)}{1+\frac{1}{\beta}\left(\sum_{\mathrm{y}=1}^{\beta} \frac{\mu_{\mathrm{x}}^{\mathrm{s}+*}}{\mathrm{O}_{\mathrm{y}_{0}}^{\mathrm{S}}}\right)}
$$

\subsection{Indicators and Data Sources}

Based on the framework in chain structure and the data requirements of the network DEA model, the research chooses the number of undergraduates in HES, the number of full-time teachers, and the expenditure for HES from two aspects, human resources and capital, to reflect the input of the first stage, "learning to research". 
The number of $R \& D$ employees is used as the output of the first stage. Then, the number of R\&D employees, expenditure for R\&D, and the stock of fixed assets were used as the inputs of the second stage, "research to production". The number of scientific papers, number of authorized patents generated in the process of URI, and the level of economic development were used as the outputs of the second stage.

Due to the data requirement of the network DEA model, the research needs to collect data of several years from many countries. The research selected data from 50 countries in 1996-2019. The higher education systems of these countries have relatively complete data and are distributed in all major continents. Firstly, data on input and intermediate indicators can be obtained from the UNESCO database [4]. The stock of fixed assets refers to the input of scientific research equipment and sites and the research calculates it by the perpetual inventory method.

Among output indicators, invention patents should be the authorized patents produced by the cooperation of URI, not the patent completed by the enterprise itself or the patent that does not take effect. With the help of the World Intellectual Property Organization (WIPO) [5]'s advanced patent search function, the research sets the following three search conditions to obtain the number of patent applications: (1) select the name of the country to be counted; (2) only count the number of invention patents, excluding the number of utility model patents, appearance patents and plant patents. Because the technical value of invention patents is significantly higher than other types. (3) The inventor's workplace must contain the words like "University" or "College" to ensure that the invention patent can be completed by the enterprise and HES collaboratively, rather than by the enterprise itself. Then, the research gets the total authorization rate of patents from WIPO's reports of World Intellectual Property indicators, and multiply by the number of applications obtained before, thus the research can infer the number of authorized invention patents generated by URI collaborative innovation.

The number of scientific papers in each country can be counted through the advanced retrieval function of Web of Science, and the statistical scope is limited in the Scientific Citation Index.

As for the level of economic development, the research uses DMSP/OLS nighttime light data to quantify it. The research adopted the DMSP/OLS nighttime light data provided by National Oceanic and Atmospheric Administration (NOAA) [6]. The total light intensity will be used as an indicator to measure a country's economic development level.

Table 1: Input, intermediate and output indicators of network DEA model

\begin{tabular}{|c|c|c|c|}
\hline & Stage & Index & Unit \\
\hline \multirow{5}{*}{ Input } & 1 & Number of undergraduates in HES & Person \\
\hline & 1 & Number of full-time teachers & Person \\
\hline & 1 & Expenditure for HES & Dollar \\
\hline & 2 & Expenditure for $R \& D$ & Dollar \\
\hline & 2 & The stock of fixed assets & Dollar \\
\hline Intermediate & $1 / 2$ & Number of R\&D employees & Person \\
\hline \multirow{4}{*}{ Output } & 2 & $\begin{array}{l}\text { Number of authorized invention patents } \\
\text { in collaborative innovation }\end{array}$ & Term \\
\hline & & & \\
\hline & 2 & Number of scientific papers & Piece \\
\hline & 2 & Level of economic development & - \\
\hline
\end{tabular}




\section{CONCLUSION}

\subsection{Visualization of Sustainability Score and Summary}

From the above, the research finally calculated the accurate stability score of HES in 50 countries (Table 2). To reach more efficient conclusions, the research makes a visualization of sustainability scores (Figure 1).

Table 2: Accurate sustainability scores in 50 countries

\begin{tabular}{cc|cc|cc}
\hline Country & $\begin{array}{c}\text { Sustainability } \\
\text { Score }\end{array}$ & Country & $\begin{array}{c}\text { Sustainability } \\
\text { Score }\end{array}$ & Country & $\begin{array}{c}\text { Sustainability } \\
\text { Score }\end{array}$ \\
\hline Argentina & 0.3653 & Hungary & 0.2673 & Russia & 0.2455 \\
Australia & 0.5497 & India & 0.1445 & Saudi Arabia & 0.1263 \\
Austria & 0.3126 & Indonesia & 0.1627 & Serbia & 0.2053 \\
Belgium & 0.4869 & Iran & 0.0951 & Singapore & 0.5640 \\
Brazil & 0.1845 & Ireland & 0.5681 & Slovakia & 0.2582 \\
Bulgaria & 0.2932 & Israel & 0.4258 & Slovenia & 0.2985 \\
Canada & 0.4727 & Italy & 0.3895 & South Africa & 0.2770 \\
Chile & 0.3787 & Japan & 0.7023 & Spain & 0.4666 \\
China & 0.3185 & Korea & 0.4873 & Sweden & 0.6852 \\
Croatia & 0.2058 & Malaysia & 0.2419 & Switzerland & 0.5291 \\
Czech Republic & 0.2754 & Mexico & 0.3336 & United Arab & 0.3777 \\
Denmark & 0.5057 & Netherlands & 0.4618 & Thailand & 0.1917 \\
Finland & 0.3814 & New Zealand & 0.6150 & Turkey & 0.2236 \\
France & 0.7752 & Norway & 0.5692 & Ukraine & 0.2539 \\
Germany & 0.6681 & Poland & 0.3516 & United Kingdom & 0.6671 \\
Greece & 0.1421 & Portugal & 0.3938 & United States & 0.8133 \\
Luxembourg & 0.4279 & Romania & 0.2174 & Brazil-0.1845); \\
\hline
\end{tabular}

(Australia-0.5497 > Brazil-0.1845); thirdly, while

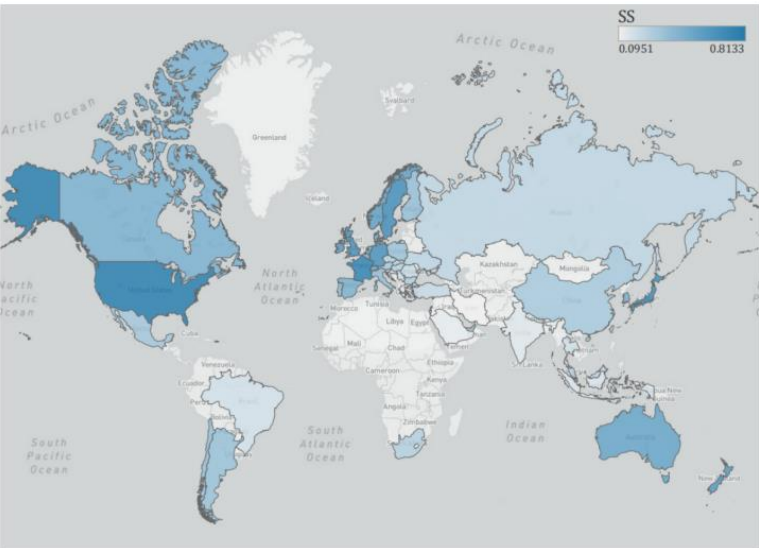

Figure 1: Visualization of Sustainability Scores in 50 countries

Combined with figure 1 and table 2 , it can see that the scores have four trends from high to low, firstly, neighboring countries have similar scores, take Europe as an example, along the $50^{\circ} \mathrm{N}$ line from west to east, the scores of various countries show a monotonous and decreasing trend (France-0.7752 > Germany-0.6681 > Poland-0.3516 > Ukraine-0.2539 > Russia-0.2455); secondly, while developed countries have higher scores, developing countries have lower scores densely populated countries have higher scores, sparsely populated countries have lower scores (United States-0.8133 > Canada-0.4727); at last, while countries with higher scores are geographically clustered around the Atlantic coast and the Western Pacific coast, which are all in the temperate areas, countries with lower scores are mainly distributed in high latitudes and near the equator.

\subsection{Policy Suggestion}

According to Item 4 of the Sustainable Development Goals (SDGs) of the United Nations, sustainable development of education should be achieved worldwide by 2030. The SDGs stress the importance of ensuring inclusive and equitable quality education and promoting lifelong learning opportunities for all. Referring to the requirements of SDGs, the research takes 2021 as the starting year of the proposed policy and 2030 as the closing year of our proposed policy.

The ratio of higher education expenditure to total education expenditure and the ratio of R\&D expenditure to total fiscal expenditure have positive effects on SS The research take increasing the proportion of them as the primary policy and other six secondary policies (Figure 2). 


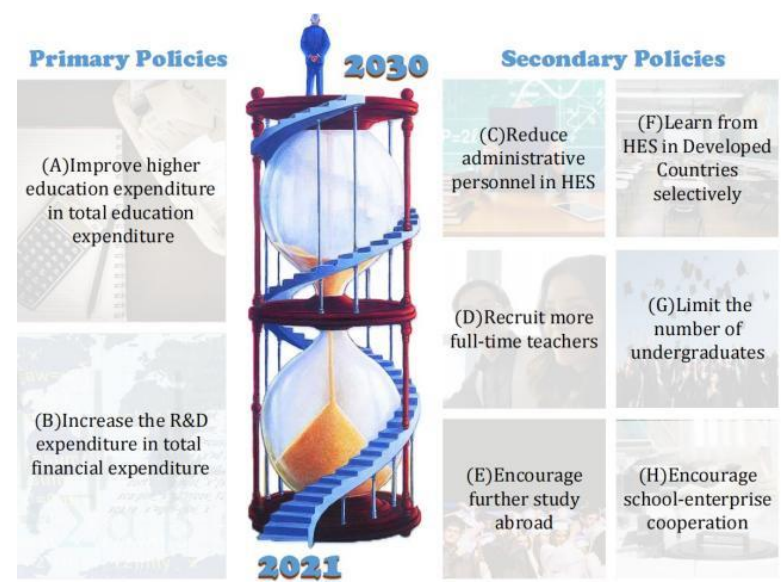

Figure 2: policy suggestion

\section{REFERENCES}

[1] Song Wang."Collaborative innovation efficiency: From within cities to between cities -Empirical analysis based on innovative cities in China", Growth and Change, 2021

[2] Song Wang."The hidden mediating role of innovation efficiency in coordinating development of economy and ecological environment: evidence from 283 Chinese cities", Environmental Science and Pollution Research, 2021

[3] Fare, R., Grosskopf, S., \& Norris, M. (1994). Productivity growth, technical progress and efficiency change in industrialized countries. American Economic Review, 84, 66-83.

[4] UNESCO database. http://data.uis.unesco.org/

[5] World Intellectual Property Organization. https://www.wipo.int/portal/en/index.html

[6] National Oceanic and Atmospheric Administration (NOAA).https://www.ngdc.noaa.gov/eog/dmsp/do wnloadV4composites.htm 